for long periods, and be easily sterilized. Two layers of silk and eight double layers of surgical gauze form mechanically efficient masks, but fall short on the other counts. Trials have therefore been made with various patterns of four-layered fine dental gauze masks.

A mask of the following design, adopted for use in the Jessop Hospital, consists of an upper and lower part ; where the two join, the corners are mitred to form a "snout." This has rendered the mask less oppressive than the oblong mask; it fits snugly at both sides and beneath the chin. Masks of this pattern have been made by Messrs. Robinson and Sons, Ltd., Chesterfield, to whom thanks are due for their unfailing patience in preparing many types before the final pattern evolved. (See Fig. 2.)
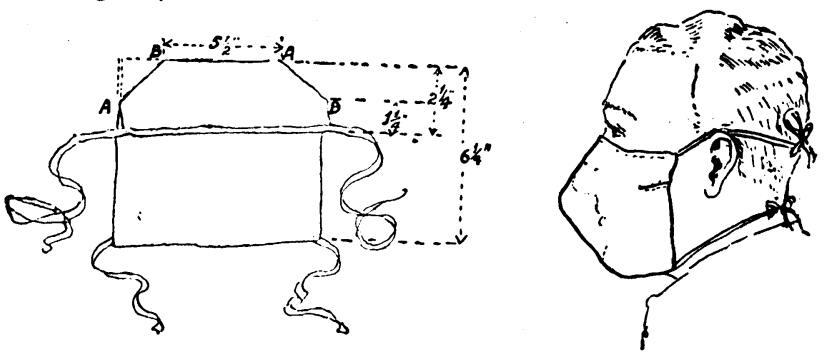

FIG. 2.-Specification for face masks. The material for the fine dental gauze face masks nusst contain fifty warp threads and forty-four weft threads per inch square of the bleached gauze, and weigh 600 grains per square yard.

\section{Discussion and Conclusions}

Haemolytic streptococci are undoubtedly responsible for a large part of puerperal morbidity. There appear to be several modes of infection. It may be carried by the hands of accoucheurs, by direct spraying from the nose or throat of attendants, or by the patient's own hands. Hand transference by the obstetric attendant occurs in four ways: by carriage of septic material from some other case; by the hands being the site of some trivial lesion, unsuspectedly harbouring haemolytic streptococci ; by the hands having been soiled from the pocket handkerchief by haemolytic streptococci; and, finally, by his hands having been infected by lowmomentum droplets from his own throat. The precautions necessary to overcome such external contamination are the use of suitable masks and the adherence to a rigid technique of hand toilet (Colebrook). It must be strongly emphasized that masking should be done before anything else-hand toilet, setting out of instruments, etc.-is commenced.

In some centres where masks are not used puerperal infection is uncommon. This would suggest that masks are of little value; but in some of these centres a rigid system of hand toilet is practised rigorously before every vaginal examination, etc., is made, thus dealing with hand contamination by low-momentum droplets. Their success depends upon the prevailing discipline. Where this cannot be guaranteed, masking as the first step in the aseptic toilet should be practised.

For institutions the value of bacteriological control cannot be overrated. Patients known to be throat carriers should be warned of the danger of hand transference. In cases of heavy upper respiratory tract infection the patient's hands should be treated with antiseptics. In addition, if every midwife and every maternity centre were supplied with a notice embodying simple details of a standardized technique, a marked diminution in the morbidity might be expected.

I would like to thank Professor M. H. Phillips for his help and kind permission to publish clinical notes, and Professor Edington for details of the case of infection following throat carriage.

\section{BIBLIOGR:PHY}

Blackburn et al.: Principles of Bacteriology and Immunity, Topley and Wilson, London, 1930, ii, 1082.

Burt-White, H., and Armstrong, R.: Proc. Roy. Soc. Med., 1928, xxi, 592.

Colebrook, L.: British Medical Journal, 1933, ii, 723.

Colebrook, L., and Maxted, W.: Journ. Obstet. and Gynaecol. British Empire, 1933, xl, 966.

Courmont, P., and Sedallion, P.: Presse Méd., 1931, xxxix, 1325

FitzGibbon, G., and Bigger, J.: British Medical Journal, 1925, i, 773.

Fleming, A., and Allison, V.: Brit. Journ. Exper. Path., 1927. viii, 214.

Kanter, A., and Pilot, I.: Surg., Gynecol. and Obstet., 1924, xxxviii, 96.

King, W.: British Medical Journal, 1930, i, 533.

Meleney, F., Zayzteff, H., Harvey, H., and Zau, Z.: Journ. Exper. Med., 1928, xlviii, 299

Paine, C.: British Medical Journal, 1931, ii, 1082.

Smith, J.: Report No. 1, Scottish Scientific Advisory Committee, Department of Health for Scotland, 1931.

Idem: Journ. Obstet. and Gynaecol. British Empire, 1933, xl, 991.

Williams, A., Nevin, M., and Gurley, C.: Journ. Immunol., 1921, vi, 5 .

Williams, J.: Journ. Amer. Med. Assoc., 1932, xcix, 1991.

\section{A CONCENTRATED LIVER EXTRACT FOR PARENTERAL ADMINISTRATION IN} PERNICIOUS ANAEMIA

BY 、

E. F. SCOWEN, M.D.

SECOND ASSISTANT, MEDICAL PROFESSORIAL UNIT, ST. BARTHOLOMEW'S HOSPITAL

AND

A. W. SPENCE, M.D., M.R.C.P.

FIRST ASSISTANT, MEDICAI, PROFESSORIAI. UNIT, ST. BARTHOLONEW'S HOSPITAL.

Since the demonstration by Minot and Murphy of the efficacy of liver in the treatment of pernicious anaemia, the active principle has been produced in concentrated extracts, although efforts to isolate the haemopoietic substance have so far not been very successful. The earlier extracts admittedly obviated the necessity of ingesting large quantities of liver, but their potency was unreliable, and many could be scarcely called palatable. These difficulties were eventually overcome, but the extracts were expensive. The subsequent discovery that dried stomach was effective by mouth was an important advance, but it still required the daily administration of preparations which were often unpleasant. Further, the question of absorption of the active principle of liver extracts from the gut was always in doubt in cases in which there was little response to treatment.

Another advance was the preparation of active extracts which could be administered parenterally, but here again the question of cost was a serious consideration for the the patient, and the necessity of frequent injections a handicap. The extract (pernaemon forte) which we have used in the treatment of six patients with pernicious anaemia overcomes to a certain extent both of these disadvantages. The preparation is a protein-free aqueous extract of liver, 1 c.cm. being extracted from 25 grams of liver and equivalent in activity to thirty to one hundred times this weight of fresh liver by mouth. In the following case reports it will be seen that only one injection is necessary to bring about marked clinical improvement and to raise the blood count to the normal level, and that maintenance doses are required only at one- or two-monthly intervals.

\section{Case Reports}

I

The first case was that of a married woman aged 39 years. There was a history of three years' gradual onset of weakness, palpitations, and vomiting. She was diagnosed. as a case 
of pernicious anaemia, and received liver and liver extracts by mouth at intervals for one year: no treatment for the last two years.

On admission there was marked pallor; the tongue was smooth ; there were no signs of disease of the nervous system. Blood count-red cells, 2,180,000 per c.mm. ; haemoglobin, 65 per cent. ; colour index, 1.5 ; white cells, 7,000 per c.mm. ; there was marked anisocytosis and poikilocytosis ; no nucleated red cells. Van den Bergh (indirect): 2.4 units of bilirubin per cent. A fractional test meal revealed achlorhydria even after histamine. Wassermann reaction negative.

After a ccntrol period of two weeks the patient was given $10 \mathrm{c} . \mathrm{cm}$. of pernaemon forte intramuscularly. On the third day after the injection the patient began to feel much stronger. The reticulocyte count began to rise on the third day and reached a maximum of 13 per cent. on the fifth. This was followed by a progressive rise in red cells and haemoglobin, until at the end of four weeks the blood count was: red cells, $4,900,000$ per c.mm. ; haemoglobin, 90 per cent. After this the red cells and haemoglobin began to fall, and a further $5 \mathrm{c.cm}$. of pernaemon forte was injected. The patient was then discharged, and attended as an out-patient. A blood count was done every two weeks, and further injections of $5 \mathrm{c} . \mathrm{cm}$. were administered whenever the blocd count began to fall. By this means the blood count has been kept at a normal level, and the patient states that she feels "better than she has done for years." The interval between the injections has varied from six to eight weeks.

A single woman, a cook aged $\mathbf{5 2}$ years, had a history of two years' gradual onset of tiredness and lack of energy ; for eighteen months she had had an unpleasant taste in the mouth ; five months before admission she had to stop work because of weakness; for one month there had been nausea and frequent vomiting; she became bed-ridden. There was occasional numbness of fingers; no sore tongue.

On admission pallor was marked; the tongue was smooth; there were no signs of disease of the nervous system. Blood count-red cells, $1,310,000$ per c.mm. ; haemoglobin, 38 per cent. ; colour index, 1.4 ; white cells, 5,600 per c.mm.; there was marked anisccytosis and poikilocytosis, but no nucleated red cells. Van den Bergh (indirect): 4 units of bilirubin per cent. Fractional test meal showed achlorhydria even after histamine.

After five days the patient was given $5 \mathrm{c} . \mathrm{cm}$. of pernaemon forte intramuscularly. On the third day there was marked clinical improvement; she began to gain in strength and to experience a feeling of well-being. The reticulocyte response began on the fifth day and reached a maximum of 12 per cent. on the sixth. The red cells and haemoglobin rcse progressively for three weeks (red cells to $3,700,000$ per c.mm., haemoglobin to 64 per cent.), and then improvement ceased. It was thought that the initial dose of pernaemon was insufficient. When another $5 \mathrm{c} . \mathrm{cm}$. was injected the blood count rose steadily, with no further response of reticulocytes, to $4,500,000$ red cells per c.mm., and 90 per cent. haemoglobin. On discharge she attended as an out-patient every two weeks. She received a maintenance dose of $5 \mathrm{c} . \mathrm{cm}$. of pernaemon whenever the blood count began to fall. The interval between the injections has varied from four to six weeks. Her blood count at present is : red cells, 4,800,000 per c.mm. ; haemoglobin, 100 per cent.

\section{III}

A costermonger, married, aged 55 years, gave a three years' history of gradual onset of tiredness and weakness, followed later by paraesthesiae in hands and feet, soreness of tongue, and dyspnoea on exertion. One year ago he was admitted as a case of pernicious anaemia and treated with hepatex, with improvement. On discharge he discontinued treatment, and his symptoms gradually returned.

On admission pallor was marked ; the tongue was smooth; there were changes in the sensation over the feet suggesting early disease of the nervous system. Blood count-red cells, $1,830,000$ per c.mm. ; haemoglobin, 48 per cent. ; colour index, 1.3 ; white cells, 5,000 per c.mm. ; there was marked anisocytosis and poikilocytosis and a few normoblasts ; no megalcblasts were seen. Van den Bergh (indirect): 2.4 units of bilirubin per cent. Fractional test meal: achlorhydria even after histamine. Wassermann reaction negative.
The patient was given 5 c.cm. of pernaemon forte intramuscularly. On the second day there was marked clinical improvement; on the third day the reticulocytes began to rise, and on the fourth reached a maximum of 2.2 per cent. There was a progressive improvement in the blood count for three weeks, the red cells rising to $3,060,000$ per c.mm. and the haemoglobin to 68 per cent. After a second dose of 5 c.cm. of pernaemon, the blood count continued to rise, although no further reticulocyte response was observed. Five weeks after the first injection the blood count was-red cells, $4,610,000$ per c.mm. ; haemoglobin, 90 per cent. The patient was discharged, and as an out-patient his blood count has been maintained at a normal level by injections of 5 c.cm. of pernaemon at intervals of four to six weeks.

\section{IV}

A grocer, married, aged $\mathbf{5 4}$ years, for two years had had a gradual onset cf lassitude and exhaustion; for three months there had been sore tongue, numbness of legs, muscular weakness, and fainting attacks.

On admission he was pale; the tongue was.smooth; there were early signs of subacute combined degeneration. Blood count-red cells, $2,020,000$ per c.mm. ; haemoglobin, 60 per cent. ; colour index, 1.5 ; white cells, 5,900 per c.mm. ; there was poikilocytosis and anisocytosis, but no nucleated red cells. Van den Bergh (indirect): $\mathbf{0 . 4}$ anit of bilirubin per cent. Fractional test meal: achlorhydria even after histamine. Wassermann reaction negative.

The patient received $8 \mathrm{c} . \mathrm{cm}$. of pernaemon forte, by intramuscular injection. Reticulocytosis began on the fourth day, and reached a maximum of 22 per cent. on the fifth. Following this there was a progressive rise of red cells and haemoglcbin-4,800,000 red cells per c.mm. and 92 per cent. haemoglobin three weeks after the injection. On discharge he attended the cut-patient department every two weeks. Fis blood count has remained normal with injections of 5 c.cm. at intervais of five to eight weeks. He has had no soreness of the tongue since treatment began.

A married woman, aged 62 years, hàd for four years complained of slight weakness, fatigability, and shortness of breath. For two years weakness had been more marked and walking difficult. For one year appetite had been failing and food had lost its taste; there was frequent nausea. For eight months there had been soreness of tongue, which has persisted ; for four months there had been paraesthesiae in the hands.

On admission she was pale; the tongue was smooth; there were no signs of disease of the nervous system. Blood count -red cells, 2,000,000 per. c.mm. ; haemoglobin, 62 per cent. ; colour index, 1.5 ; white cells, 6,000 per c.mm. ; there was marked poikilocytcsis and anisocytosis, and nucleated red cells were present, but no megaloblasts. Van den Bergh (indirect): 1.6 units of bilirubin per cent. Fractional test meal: achlorhydria even after histamine. Wassermann reaction negative.

After $8 \mathrm{c.cm}$. of pernaemon forte had been injected intramuscularly, reticulocytosis began on the third day, and on the fifth rose to a maximum of 15 per cent. There was a progressive rise of red cells and haemoglobin; and one week after the injection her general health was greatly improved. A second injection of $5 \mathrm{c} . \mathrm{cm}$. was given four weeks after the first; a week later her blood count was: red cells, $4,700,000$ per c.mm. ; haemoglobin, 96 per cent. She has recently been discharged.

\section{VI}

A fish frier, married, aged 61 years, gave a history of shortness of breath and weakness for eight years. He was diagnosed as a case of pernicious anaemia six years ago and treated with liver; he greatly improved, but discontinued treatment. Later he had liver off and on when he felt his symptoms returning ; but had had no liver for the past seven months. He had been bed-ridden for the past two months with dyspnoea and weakness. He complained of occasional tingling of the fingers; no soreness of tongue.

On admission there was marked pallor ; he was delirious and unable to answer questions or talk rationally. The tongue was not smooth ; there were marked signs of subacute combined degeneration. His condition was considered so serious that immediately on admission $10 \mathrm{c} . \mathrm{cm}$. of pernaemon forte was injected intramuscularly. For three days he remained 
stuporous, with an occasional lapse into noisy delirium. On the third night he was given $\mathbf{0 . 8} \mathrm{mg}$. of hyoscine, which had to be repeated in four hours. When he had recovered from the effects of the hyoscine he was completely rational, and remained so.

On admission his blood count was-red cells, $1,150,000$ per c.mm. ; haemoglobin, 33 per cent. ; colour index, 1.35 ; white cells, 2,800 per c.mm. ; anisocytosis and poikilocytosis was marked; there were a few nucleated red cells, but no megaloblasts were seen. Fractional test meal: achlorhydria even after histamine. Reticulocytosis began on the third day and reached a maximum of 26 per cent. on the fourth. During the next four weeks there was a steady rise of red cells $(3,400,000$ per c.mm.) and haemoglobin (70 per cent.). $\mathrm{He}$ was then given a further $5 \mathrm{c} . \mathrm{cm}$. of pernaemon, and at the end of another four weeks his blood count was: red cells, 4,500,000 per c.mm.; haemoglobin, 92 per cent. There was no very marked change in the condition of his nervous system: his gait was very ataxic, but his knee-jerks, which were previously absent, could now be elicited, and his plantar responses, which on admission were extensor, were now equivocal. To determine whether larger doses would produce any improvement in his nervous condition he received three injections of $20 \mathrm{c.cm}$. pernaemon forte at intervals of twelve days. During this time the right plantar response became more normal in type and his walking greatly improved. The patient has recently been discharged with a normal blood count.

\section{Comment}

In all the cases treated there was a dramatic response following a single intramuscular injection of pernaemon forte. On the third or fourth day the patients experienced a return of strength and a sense of well-being. This often preceded, but sometimes coincided with, the beginning of the reticulocyte response. Reticulocytosis usually started on the third or fourth day, and rose to a maximum on the fifth or sixth. In three cases the maximum response did not rise above 15 per cent. We have no explanation for this. The technique was the same throughout, and the reticulocyte count was performed daily at approximately the same time. It is improbable that the height of the response was missed. The degree of reticulocytosis bore no relation to the eventual rise of red cells. A reticulocyte rise was not observed after subsequent injections.

If the initial dose of pernaemon forte was adequate, the red cells and haemoglobin increased steadily after a single injection to reach a normal figure in four or five weeks. Two cases, however, which had received an initial dose of $5 \mathrm{c} . \mathrm{cm}$. failed to touch a normal level until a second dose was given.

As a rule, an initial dose of $8 \mathrm{c} . \mathrm{cm}$. of the preparation appears to be adequate, but in severe cases a dose of $10 \mathrm{c} . \mathrm{cm}$. is desirable. When the blood count has returned to normal figures, it has been found possible to keep it at this level by means of a maintenance dose of $5 \mathrm{c} . \mathrm{cm}$. injected intramuscularly at intervals varying from four to eight weeks. This interval varies not only from patient to patient but in each individual from time to time. A blood count should be done every two weeks, and any indication of a fall calls for a further injection. We have found that patients do not greatly dislike these injections, and are grateful not to be forced to take liver or liver preparations by mouth. Three patients in our series had discontinued taking liver or liver preparations by mouth, partly because of the nausea they produced and partly because of the expense. The soreness of the tongue, when present, rapidly disappeared, and has not recurred during treatment. The effect on subacute combined degeneration, which was present in Case VI, was doubtful.

The advantages of this preparation lie in the infrequency of the injections and the relative cheapness of its administration. With other parenteral preparations, in the early stages of treatment an injection is required every day,

and later a maintenance dose is necessary at least once a week. With regard to the question of cost, this is of great importance to the patient, as treatment has to be continued for the rest of his life. In $1933 \mathrm{Dr}$. L. J. Witts ${ }^{1}$ tabulated the cost of daily doses of different remedies for pernicious anaemia. The cheapest of these proved to be desiccated stomach, which costs 6.4 pence per day (retail). The cost of pernaemon forte compares very favourably with this. The retail price of 5 c.cm. is $8 \mathrm{~s}$. 6d., so that an initial dose of $8 \mathrm{c.cm}$. averages $5 \frac{1}{2} \mathrm{~d}$. per day for the first thirty days ; thereafter a maintenance dose of $5 \mathrm{c} . \mathrm{cm}$. every four to eight weeks averages $3 \frac{1}{2} \mathrm{~d}$. to $1 \frac{3}{4} \mathrm{~d}$. per day.

\section{Summary}

1. Case reports have been given of six patients with pernicious anaemia treated with pernaemon forte, a highly active protein-free extract of liver for parenteral administration.

2. After a single intramuscular injection, $8 \mathrm{c.cm}$. usually being adequate, the blood returned to normal within four or five weeks.

3. With a maintenance dose of $5 \mathrm{c.cm}$. every four to eight weeks the blood count could be kept at a normal level.

4. The cost of the preparation compares very favourably with that of other remedies for pernicious anaemia.

Our thanks are due to Professor F. R. Fraser for permission to publish these case reports, and to Dr. E. Graeme Robertson for confirming the neurological findings. One of us (A. W. S.) thanks the Medical Research Council for personal and expenses grants.

We are indebted to Dr. A. Macbeth of the Organon Laboratories for generous supplies of pernaemon forte.

Reference

${ }^{1}$ Witts, L. J.: Proc. Roy. Soc. Med., 1933, xxvi, 607.

\section{RETROGRADE JEJUNO-GASTRIC INTUSSUSCEPTION, ACUTE AND CHRONIC}

\section{BY}

\author{
A. WILFRID ADAMS, M.S., F.R.C.S. \\ SURGEON, BRISTOL ROYAL INFIRMARY
}

Past monographs on this rare sequel of gastro-enterostomy have been scanty. Standard textbooks, such as Moynihan's Abdominal Operations and Hamilton Bailey's Emergency Surgery, ignore it. The acute variety is nevertheless a ghastly reality when it does occur, and well deserves its place on the roll of abdominal catastrophes. It means to the patient an impending tragedy from which, however, timely surgical aid can readily rescue him. This fact and its simple pathology should commend it to the memory of medical men. The literature has chiefly dealt with the acute type. This may be due, not to its greater frequency, but rather to its dramatic and often fatal nature compared with the chronic cases. Certainly both types deserve a sure place in the minds of surgeons who perform the operation that causes them and of physicians who may have to diagnose them.

\section{Case Record}

Interest in the subject has been aroused by the following case :

A married woman, 72 years of age, had abdominal comfort ever since an operation on the stomach eighteen years previously. Suddenly, on February 27th, 1934, and after a week's indigestion, she was seized with acute abdominal pain. Incessant vomiting ensued, enemata failed to evoke any response, and she was admitted to the Bristol Royal Infirmary as a case of acute intestinal obstruction on March 1st. 